\title{
A Simple Negative Torque Compensation Scheme for a High Speed Switched Reluctance Motor
}

\author{
Dong-Hee Lee ${ }^{\dagger}$, So-Yeon Ahn*, and Jin-Woo Ahn* \\ $\dagger *$ Dept. of Mechatronics Eng., Kyungsung University, Busan, Korea
}

\begin{abstract}
SRMs(Switched Reluctance Motors) are much interested in high speed applications due to the mechanical robustness, simple structure and high efficiency. In spite of many advantages of SRMs, a higher torque ripple discourages the adoption of SRMs in a high speed application. This paper presents a simple negative torque of tail current compensation scheme using a modified TSF(Torque Sharing Function) for the high speed SRMs. Because of the short commutation in the high speed region, the negative torque from the tail current makes the high torque ripple. In order to reduce and compensate the negative torque from tail current, the proposed control scheme produces an additional compensating torque with a reference torque in the active phase winding. And the compensating value is dependent on the tail current of the inactive phase winding. Furthermore, the switching signals of the outgoing phase are fully turned off to restrict the extended tail current, and the torque error of the outgoing phase is compensated by the incoming phase. The proposed modified TSF control scheme is verified by the computer simulations with 30,000[rpm] high speed 4/2 SRM. The simulation and experimental results show the effectiveness of the proposed control scheme.
\end{abstract}

Key Words: High speed, Modified Torque Sharing Function, Switched Reluctance Motor

\section{INTRODUCTION}

High speed drive systems are much interested in the industrial application such as blower, compressor, pump and spindle due to the compact size and high efficiency. In recent, the demands of high speed drives are much increased due to the mechanical advantages of high speed system [1]-[4]. SRMs (Switched Reluctance Motors) have simple structure and inherent mechanical strength without rotor winding and permanent magnet. These mechanical structures are suitable for harsh environments such as high temperature and high speed applications [5]-[11]. Although SRMs have many advantages for the high speed applications, high torque ripple is still main problem to be applied to a high speed drives.

For the control of high speed SRM, a simple control schemes are introduced [2], [11]-[13]. The previously researched methods are very simple, but the motor has high torque ripple. A simple on/off angle and a constant current control schemes didn't consider the non-linear characteristics of saturated inductance. Furthermore, very short commutation period can produce the tail current in the outgoing phase winding, and the negative torque from the tail current produces an additional torque ripple.

TSF (Torque Sharing Function) control is very simple, but it uses the non-linear characteristic of the torque to current of the SRM. With the precise current controller, TSF method

Manuscript received Aug. 18, 2011; revised Dec. 13, 2011

Recommended for publication by Associate Editor Jang-Mok Kim.

$\dagger$ Corresponding Author: leedh@ks.ac.kr

Tel: +82-51-663-4693, Fax: +82-51-663-4699, Kyungsung University

* Dept. of Mechatronics Eng., Kyungsung Univ., Korea can produce a constant torque [14], [15]. However, the conventional TSF algorithm cannot consider the negative torque from the tail current, in the high speed region. When the phase current of the outgoing phase is not distinguished after the commutation region, the tail current produces a negative torque while the tail current is exhausted. In this region, the active phase winding current produces a positive torque to keep its reference value. But the total torque has high torque ripple because of the tail current torque.

And the implementation of the TSF requires a precise rotor position to calculate the torque and the current reference during over-lap region.

This paper presents a modified TSF control scheme for high speed SRM. TSF control can basically consider the non-linear characteristics of the inductance, so it can produce the flat top torque during a two-phase torque production region with the precise torque. If the outgoing and incoming phase currents can follow the reference values during commutation region, the total torque of the SRM could be constant. However, the tail current of the outgoing phase makes an additional torque ripple in the high speed region. The proposed modified TSF algorithm considers the negative torque from the tail current, and the torque reference of the active phase compensates the negative torque from the inactive phase. Furthermore, the torque sharing in the over-lap region is divided by two modes. In the general speed region, the switching of the two phases is controlled by the torque error, but the switching signals of the outgoing phase are limited in the high speed region to reduce the tail current. The outgoing phase is fully turned off, and the torque error of the outgoing phase is compensated 


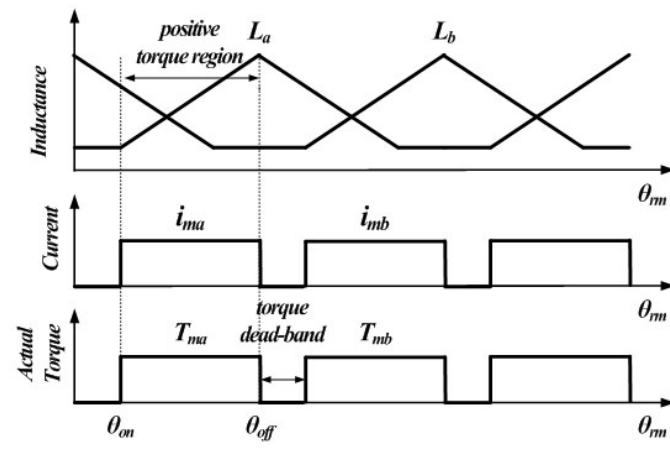

Fig. 1. Inductance and torque profiles of conventional $4 / 2$ SRM.

by the incoming phase during over-lap region. To implement the proposed control scheme, rotor position is obtained by the contactless magnetic sensor. The magnet is inserted in the shaft, and flux detecting sensor is located in the opposite side of the magnet with air gap, to bear in high speed.

The proposed control scheme is tested in the 4/2 SRM which is designed for air-blower, and the target speed is $30,000[\mathrm{rpm}]$. The proto-type high speed 4/2 SRM has asymmetric inductance profile to extend the positive torque region which is useful for the unidirectional application such as blower.

In order to verify the performance of the proposed control scheme for a high speed drive, computer simulations and experimental tests are implemented.

\section{Proto-Type 2-PhASe 4/2 SRM}

SRM has been researched in various applications. Generally, $4 / 2$ and 12/8 SRMs are applied to many industrial applications. In high speed applications, 6/2 and 4/2 SRMs are used because of less core losses and simple structure of power circuit. But core losses are a function of electrical frequency. And switching loss in power semiconductor is proportional to switching frequency, Therefore, the high electrical frequency is cause of increasing power losses in the system. With a given speed, electrical frequency in SRM is proportional to the number of rotor poles. In order to reduce power losses in high speed drives, number of rotor poles should be selected as low as possible.

As shown in Fig. 1, conventional 4/2 SRM has asymmetric inductance profile and positive torque can be produced in rising slope of inductance. There are some positions where overlap region between motoring regions of two phases is blank, i.e., dead zone. In these blank regions, there is no driving torque by the motor. When rotor position is located in the dead zones, self-starting cannot be realized. And it also has serious vibration because of high torque ripple.

In order to obtain a continuous torque with overlap region, the rotor pole arc is wider than the stator pole pitch. The output torque is dependent on the reluctance of the magnetic circuit which is dominantly determined by the air-gap between the stator and rotor pole. Dissimilar to the stepper rotor type, the continuous non-uniformed air-gap rotor is considered to reduce torque ripple around the stepper region in the proposed $4 / 2$ SRM. And, the continuous non-uniformed air-gap is optimized by the FEM analysis according to torque ripple. The output

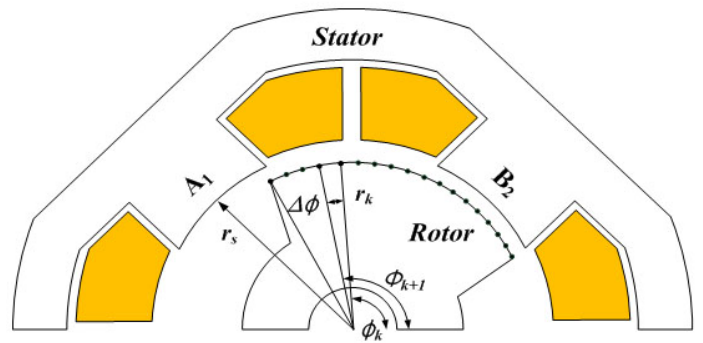

Fig. 2. Initial model for optimization.

torque is estimated by the FEM analysis according to the airgap variation. And the optimization algorithm determines the output torque which is analyzed by the FEM is proper or not. In order to satisfy the design goal, the optimization algorithm changes the air-gap. In order to optimize the air-gap, the outer radius of rotor is described by the radius and angle data in polar coordinate $\left(r_{k}, \phi_{k}\right)$ which is fixed to rotor.

Fig. 2 shows the initial model of the optimization of the rotor shape and optimization process. As shown in Fig. 2, the envelope of rotor pole is divided by n-nodes. The outer radius of rotor is connected to each node which is coordinated as radius and angle. In each node, air-gap can be obtained by the inner radius of stator pole and outer radius on each node. At the initial condition, the output torque is calculated by FEM analysis. Then, the torque data is compared with the desired value and restriction condition of torque ripple. If the torque ripple is higher than the desired condition in the optimizing node, radius of the node is adjusted to match the condition. If the torque ripple is satisfied with the condition, the next node is optimized shifting angle, $\Delta \phi$.

The various air-gap at k-th node is determined by the $r_{k}-r_{s}$. And the k-th radius $r_{k}$ is changed to reduce torque ripple in the limited band. At the k-th node, output torque is higher than the desired one, radius $r_{k}$ is decreased to reduce the output torque. And, if the output torque is lower than the desired one, the radius $r_{k}$ is increased to satisfy the output torque. The maximum radius is limited by the minimum air-gap.

Fig. 3 shows a flow-chart for the rotor shaped optimization in the proto-type design algorithm. In the Fig. 3, the initial conditions are minimum air-gap, accepted torque error $T_{e r r}[\%]$ according to average torque $T_{\text {avg }}$, node numbers and shift step angle $\Delta \phi$. In this paper, node numbers and shift step angle $1[\mathrm{deg}]$ and accepted torque error is set to $2[\%]$. The rated output torque is set as $0.2[\mathrm{Nm}]$ for $600[\mathrm{~W}]$ high speed airblower system.

In general, fringing flux, when rotor was optimized at k-th node is being optimized. It means that optimization of next nodes will change previous torque which was calculated in previous step. Because air-gap flux dominates fringing fluxes, the fringing effect can be ignored. And optimization of nodes is treated to be independent each other.

Fig. 4 and Table I show the proposed proto-type high speed $4 / 2$ SRM and its specifications. The SRM is designed for a high speed air-blower which has 30,000[rpm] rated speed. Different from the conventional SRM, the proto-type motor has wide rotor pole arc and non-constant air-gap to produce a wide, constant positive torque region. The non-constant air- 


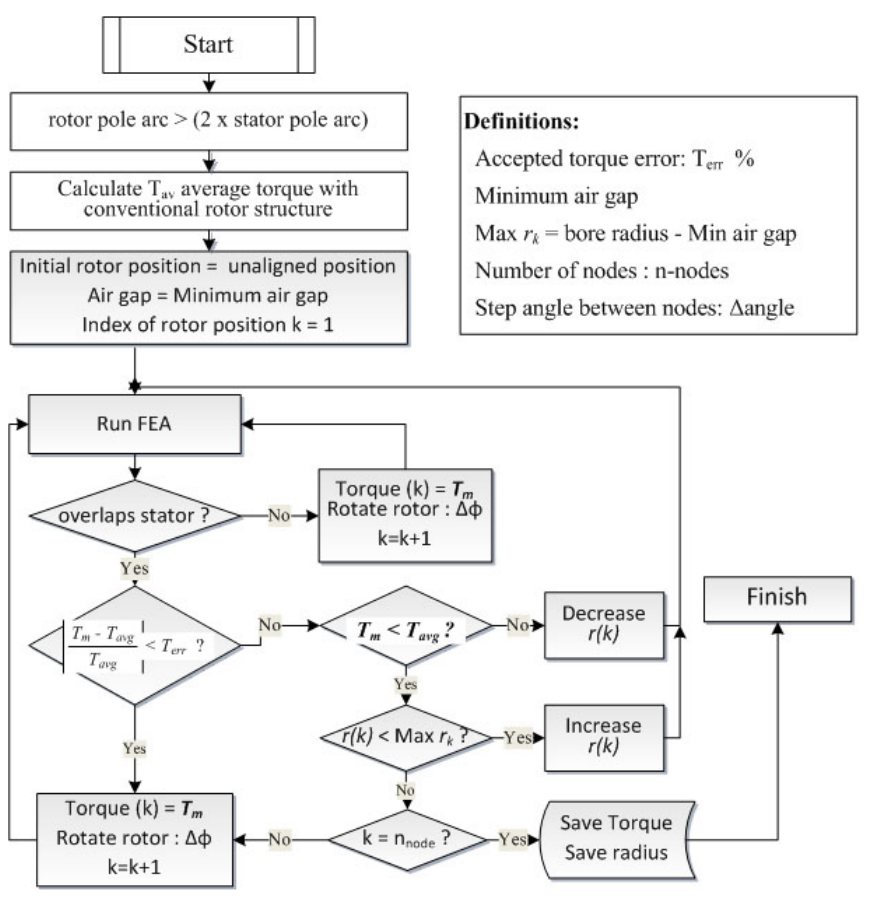

Fig. 3. Flow chart for rotor shape optimization.

gap is optimized to reduce torque ripple during the positive torque region. As the motor is designed for air-blower, so the motor is operated in one direction.

Fig. 5 shows an analyzed torque profile of the designed SRM and torque comparisons with a conventional SRM. As shown in Fig. 5, the designed 2-phase SRM has an asymmetric inductance characteristic which can produce wide positive and short negative torque region. With a consideration of saturation effect, the proposed motor is optimized at 7[A] of phase current which is the rated current of the motor. In the heavy load, torque ripple around middle of rotor pole is increased by saturation effect. However, the torque ripple of the designed motor is very low compare than a conventional SRM shown in Fig. 5(b). As shown in Fig. 5(b), a conventional 4/2 SRM has torque dead-zone where the motor cannot be self-started, and the high torque ripple is produced in the stepper type SRM.

In a high speed drive, high resolution optical encoder can not be used due to the electrical dynamics and mechanical problem of the encoder. In this paper, contactless magnetic position sensor is used to detect the precise rotor position. The permanent magnet is inserted to the end of shaft, and magnetic senor detects the flux of the magnet in the opposite position with a air-gap. It can detect the rotor position without mechanical friction with the $1024[\mathrm{ppr}]$ resolution.

\section{Proposed Modified TSF Control Scheme}

\section{A. Conventional TSF Control Scheme}

TSF algorithm is very effective torque control scheme for the SRM. It uses a simple torque sharing function in the phase over-lap region and the relationship between torque and current.

Fig. 6 shows the conventional TSF control scheme for the SRM. As shown in Fig. 6, the torque over-lap region is defined as the starting position of the inductance. During the torque

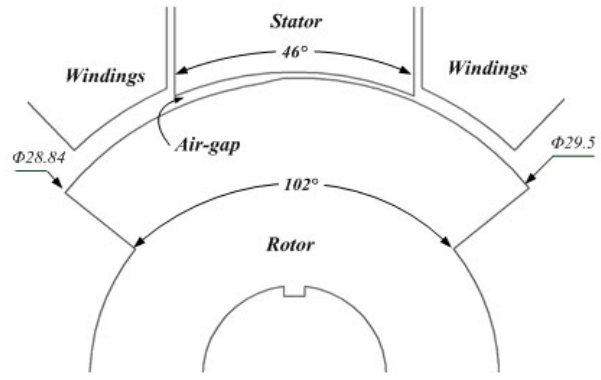

(a) Dimensions

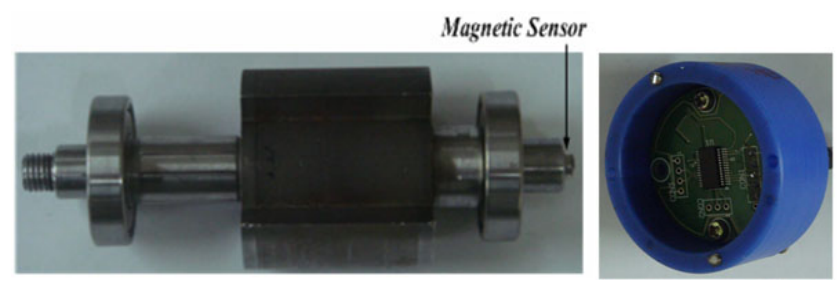

(b) Rotor.

(c) Magnetic encoder.

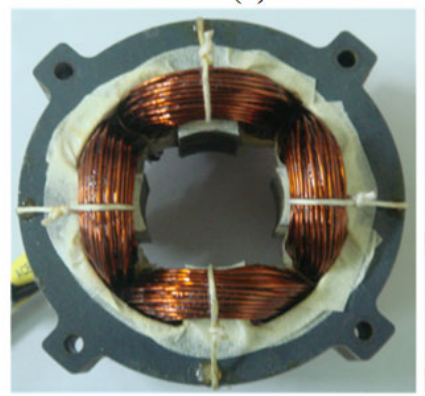

(d) Stator.

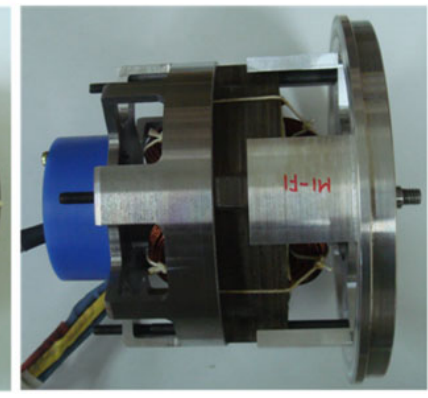

(e) Assembled SRM
Fig. 4. Proto-type high speed 4/2 SRM

TABLE I

SPECIFICATIONS OF THE PROTO-TYPE 4/2 SRM

\begin{tabular}{l|ll}
\hline Parameters & \multicolumn{2}{|c}{ Value } \\
\hline Rated output power & 600 & {$[\mathrm{~W}]$} \\
\hline Rated torque & 0.2 & {$[\mathrm{~N} . \mathrm{m}]$} \\
\hline Rated speed & 30,000 & {$[\mathrm{rpm}]$} \\
\hline Rated current & 7 & {$[\mathrm{~A}]$} \\
\hline Number of stator poles & 4 & \\
\hline Number of rotor poles & 2 & \\
\hline Bore diameter & 30 & {$[\mathrm{~mm}]$} \\
\hline Outer stator diameter & 80 & {$[\mathrm{~mm}]$} \\
\hline Stack length & 30 & {$[\mathrm{~mm}]$} \\
\hline Minimum air-gap & 0.25 & {$[\mathrm{~mm}]$} \\
\hline Stator pole arc & 46 & {$[\mathrm{Deg}]$.} \\
\hline Rotor pole arc & 102 & {$[\mathrm{Deg}]$.} \\
\hline $\mathrm{R}_{p h}$ & 0.5 & {$[\mathrm{Ohm}]$} \\
\hline $\mathrm{L}_{u}$ (unaligned inductance) & 2 & {$[\mathrm{mH}]$} \\
\hline
\end{tabular}

over-lap region, two phases are activated to produce total torque, and only one active phase produces output torque exception over-lap region. The torque sharing function during over-lap, a simple cosine and linear fucntion can be used.

The torque reference during one-phase mode of the each phases is defined as follows.

$$
\begin{gathered}
f_{T(k)}^{*}=T_{m}^{*} \\
f_{T(k-1)}^{*}=0
\end{gathered}
$$

And the torque commands during commutation are defined 


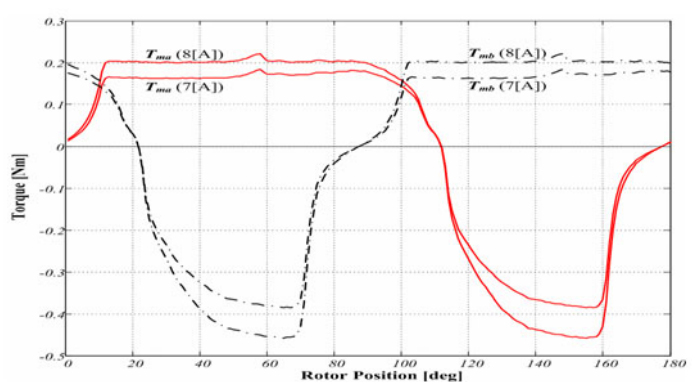

(a) Torque profile of the proposed motor.

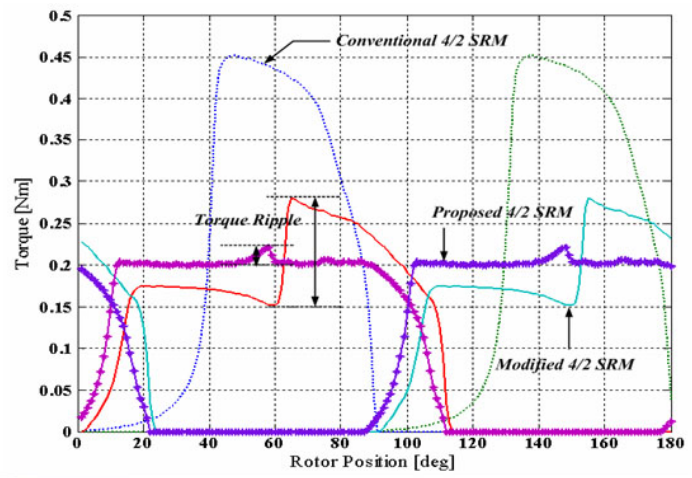

(b) Compared torque profile.

Fig. 5. Inductance and torque characteristics of the proposed 4/2 SRM.

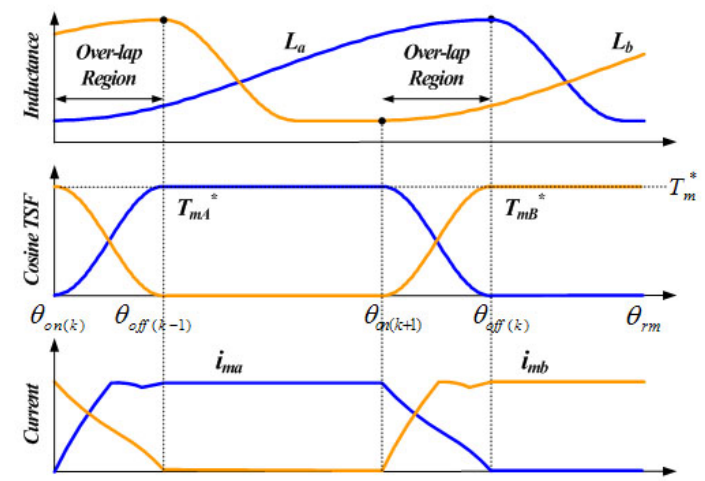

(a) Torque sharing function and current waveform.

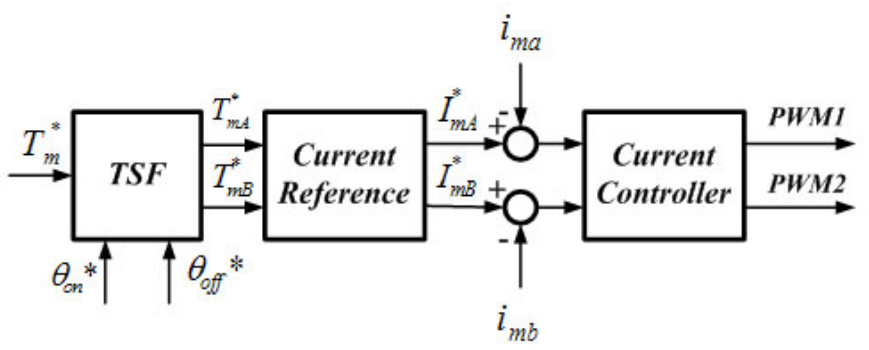

(b) Block diagram of the TSF control scheme.

Fig. 6. Conventional TSF using cosine function.

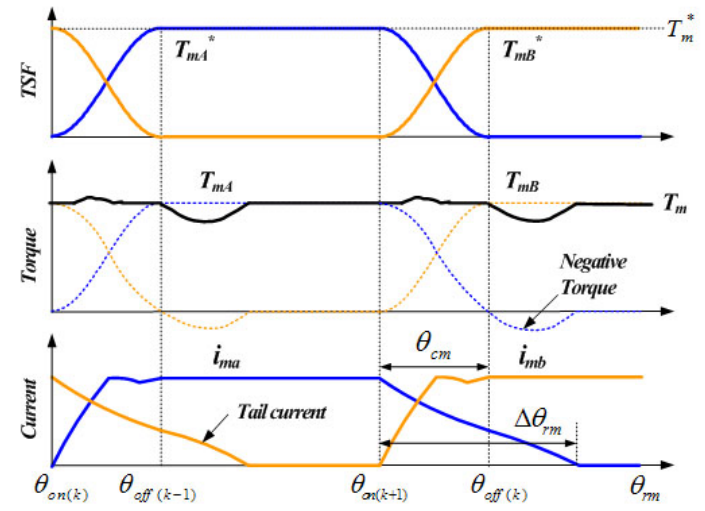

Fig. 7. Torque ripple from the tail current in high speed region.

as follows in the cosine TSF.

$$
\begin{aligned}
& f_{T(k)}^{*}=\left[1-\cos \left(\frac{\theta_{r m}-\theta_{o n(k)}}{\theta_{o f f(k-1)}-\theta_{o n(k)}} \cdot \frac{\pi}{2}\right)\right] T_{m}^{*} \\
& f_{T(k-1)}^{*}=1-f_{T(k)}^{*} .
\end{aligned}
$$

Where, $\theta_{r m}$ is rotor position. The $\theta_{o n(k)}$ and $\theta_{o f f(k-1)}$ are turn on and off angle of the incoming and outgoing phase, respectively.

The each torque references are changed to the current reference to produce the reference torque with the considerations of non-linear torque characteristics. The the controlled current can keep the reference torque.

However, the practical current cannot be kept the reference value due to the short commutation time in the high speed region. So, the tail current which is extended to the negative torque region, produces negative torque when the phase is inactive. From this tail current, the total torque of the high speed SRM has high torque ripple. Fig. 7 shows the effects of the tail current in a high speed region.

If the outgoing phase is fully turned off, the demagnetization time and angle variation of the outgoing phase can be derived as follows.

$$
\begin{gathered}
\Delta t_{f}=\frac{L_{a}\left(\theta_{o n(k)}, i_{(k)}\right) \cdot I_{m}^{*}}{V_{d c}} \\
\Delta \theta_{r m}=\omega_{r m} \cdot \Delta t_{f}
\end{gathered}
$$

Where, $\omega_{r m}$ is the motor speed, and $V_{d c}$ is dc-link voltage which is supplied during the demagnetization.

When the angle variation during demagnetization time of the ougoing phase is over than the commutation angle $\theta_{c m}$, the outgoing phase produces the tail current.

\section{B. The Proposed Control Scheme for the High Speed SRM}

In order to compensate the torque ripple from the tail current, the modified TSF control scheme is proposed in this paper. The proposed TSF has compensating torque block in the active phase.

And the compensating torque can reduce the torque ripple from the negative torque of the inactive phase in a high speed. In order to reduce the tail current during commutation region, the switching signal of the outgoing phase is fully turned off. If the phase current is not extended to the negative torque region, the switching patterns of the each phases are determined by 


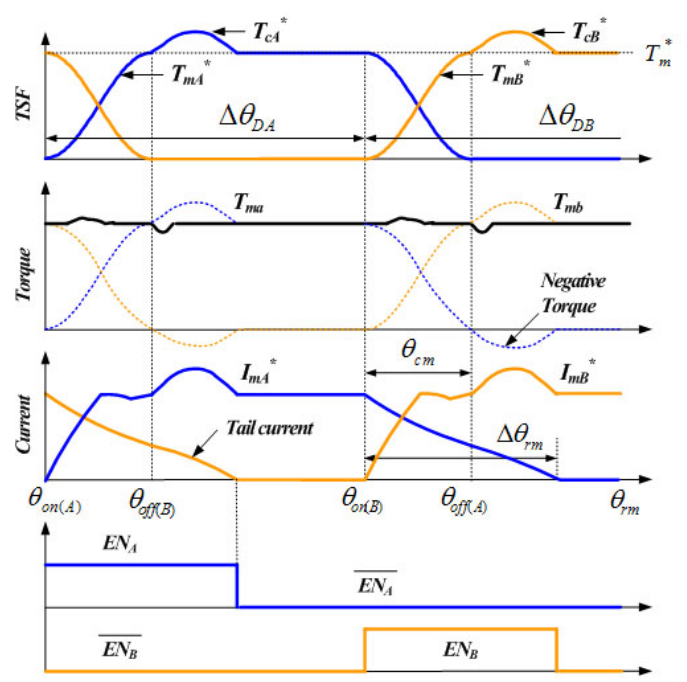

(a) Modified torque sharing function.

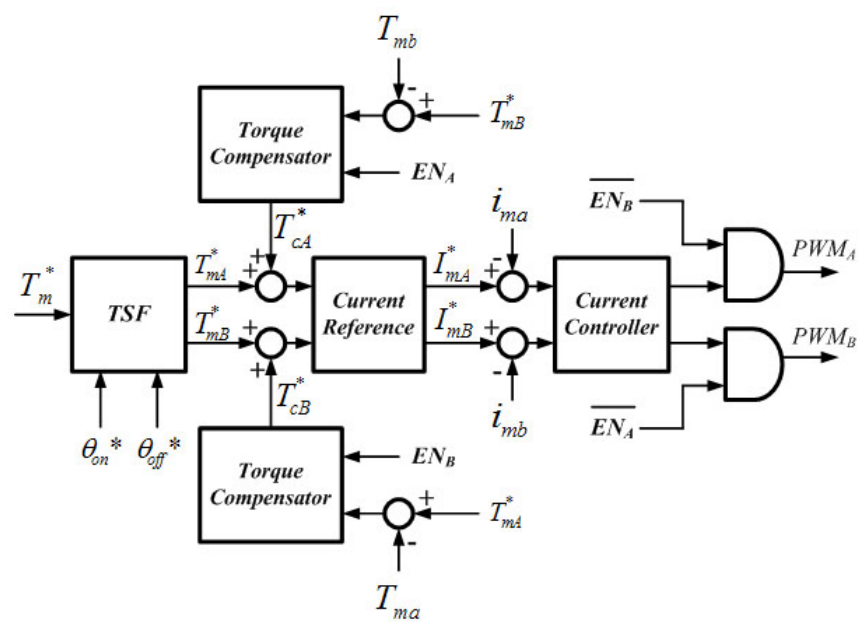

(b) Control block diagram.

Fig. 8. Proposed modified TSF control scheme.

the torque errors during commutation region. However, the swtching signals of the outgoing phase are fully turned off, when the demagentization time is over than the designed commutation angle to reduce the negative torque from the tail current. And the torque error of the outgoing phase is compensated by the incoming phase current reference. After the commutation region, the negative torque of the outgoing phase is compensated by the compensation torque of the active phase.

Fig. 8 shows the block diagram of the proposed TSF control scheme for a high speed region. Compare with the conventional TSF method shown in Fig. 6(b), it has torque compensators and PWM limit signals.

In the Fig. $8, T_{c A}^{*}$ and $T_{c B}^{*}$ are the compensatng torques for the negative torques from the tail current. In this paper, the compensating torque is simply calculated without any control gains as follows.

$$
\begin{aligned}
T_{c A}^{*} & =T_{m B}^{*}-T_{m b} \\
T_{c B}^{*} & =T_{m A}^{*}-T_{m a}
\end{aligned}
$$

Where, $T_{m A}^{*}$ and $T_{m B}^{*}$ are torque references of the each phases. And the $T_{m a}$ and $T_{m b}$ are the estimated torques which

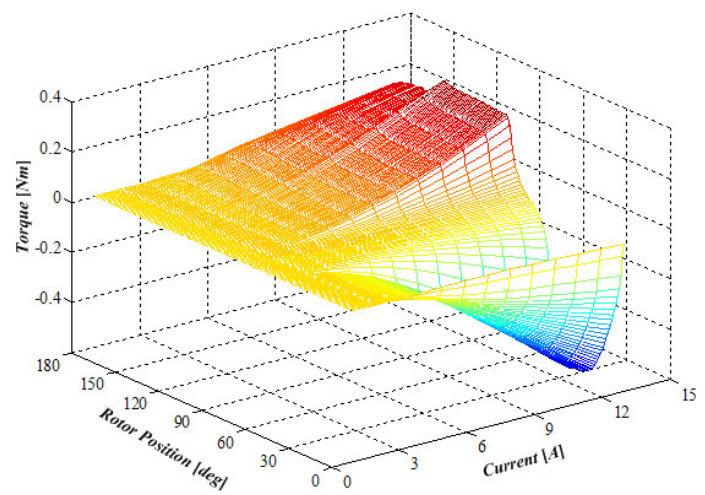

(a) Look-up table of the torque estimator.

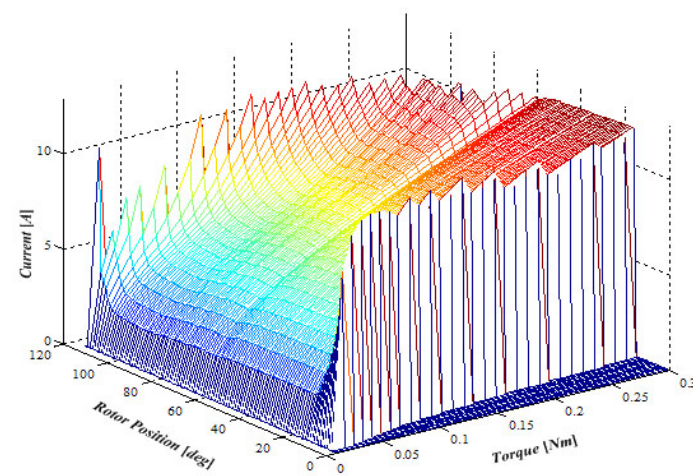

(b) Look-up table of the current reference.

Fig. 9. The torque estimator and current reference of the proto-type SRM.

are calculated by the look-up table according to the actual phase current and rotor position. In order to make the look-up table for torque estimator, the torque data are saved according to the 0 to $13[\mathrm{~A}]$ with $1[\mathrm{~A}]$ and 1 [deg.] scale. So, the look-up table has $14 \times 90$ array data. The other data are determined by the data interpolation technology.

The $E N_{A}$ and $E N_{B}$ are the enable signals for the compensation controller. The activation signal is determined as follow.

$$
\begin{aligned}
& \text { if }\left(\left(\theta_{\text {on }(A)} \leq \theta_{r m}<\theta_{\text {on }(B)}\right) A N D\left(\Delta \theta_{r m}>\theta_{c m}\right)\right) \text { then } E N_{A}=1 \\
& \text { else } E N_{A}=0
\end{aligned}
$$

The Current Reference block in Fig. 8(b) is designed as look-up table whose data are defined by the reference torque and rotor position with the non-linear characteristics of the proto-type SRM. Fig. 9 shows the torque estimator and current reference data which are used in this paper. The current controller is designed by the PI controller in this paper.

\section{Simulation Results}

In order to verify the proposed control scheme, computer simulation is implemented. The simulation model is designed by Matlab Simulink. The inductance and torque of the simulation model are designed with FEM analysis data. An asymmetric power converter and hysteresis current controller are used in the simulation. The current controller has 25[us] sampling time. And the current is directly feedback to the controller.

Fig. 10 shows the compared simulation results in the conventional TSF and the proposed control scheme at 


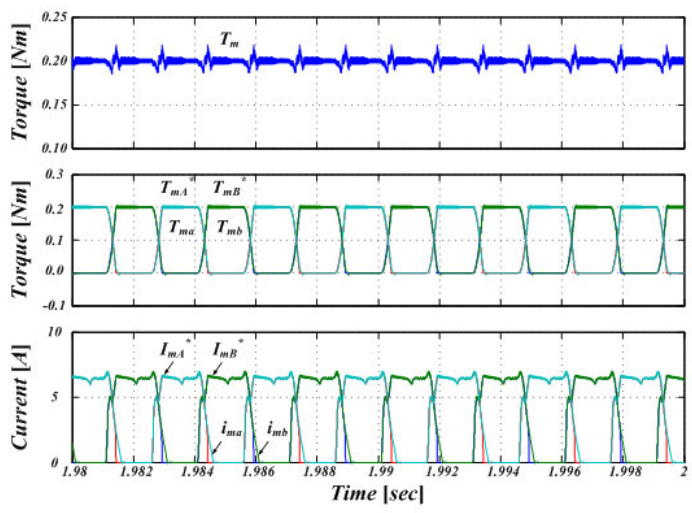

(a) Conventional cosine TSF.
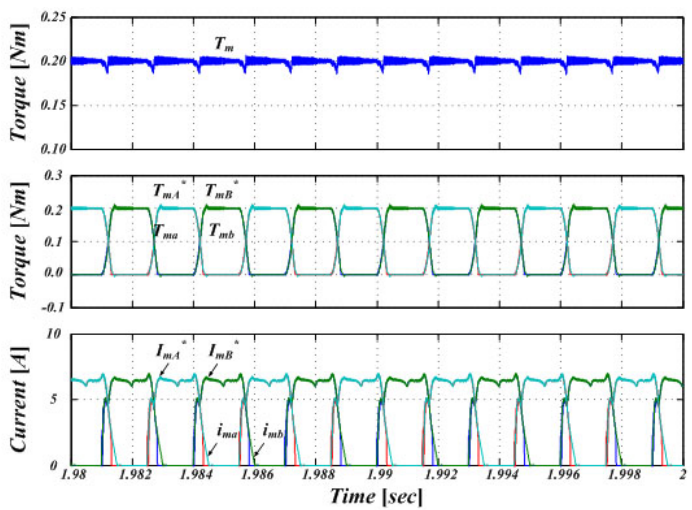

(b) Proposed TSF control scheme.

Fig. 10. Compared simulation result at 10,000[rpm].

10,000[rpm]. As shown in Fig. 10, the simulation results of the proposed type is marginally improved, and the torque ripple is almost same due to the a low tail current. In the 10,000[rpm], the negative torque is very small and the compensation effect is not much. The output torque of the high speed SRM can be controlled well by the TSF control scheme.

Fig. 11 shows the compared simulation results at $30,000[\mathrm{rpm}]$. As shown in Fig. 11, the torque ripple of the proposed control scheme is much reduced than the conventional one. The torque ripple of the conventional TSF is very serious after the commutation region due to the negative torque from the tail current of the outgoing phase winding. However, the proposed control scheme can compensate the negative torque with the active phase torque.

\section{ExPERIMENTAL RESUlts}

In order to verify the proposed control scheme, practical experiments are implemented. The proto-type SRM with heavy load fan is used in the experiments.

DSP controller designed by TMS320F2811 and asymmetric converter with power FET and diodes are used. The rotor position is detected by the contactless magnetic sensor which has 1024 pulse per revolution.

Fig. 12 shows the compared experimental results according to the control schemes at $10,000[\mathrm{rpm}]$ and no-load. In the conventional PI current controller shown in Fig. 12(a), the phase currents are well kept the reference value, but torque has ripple because of the non-linear inductance characteristics.

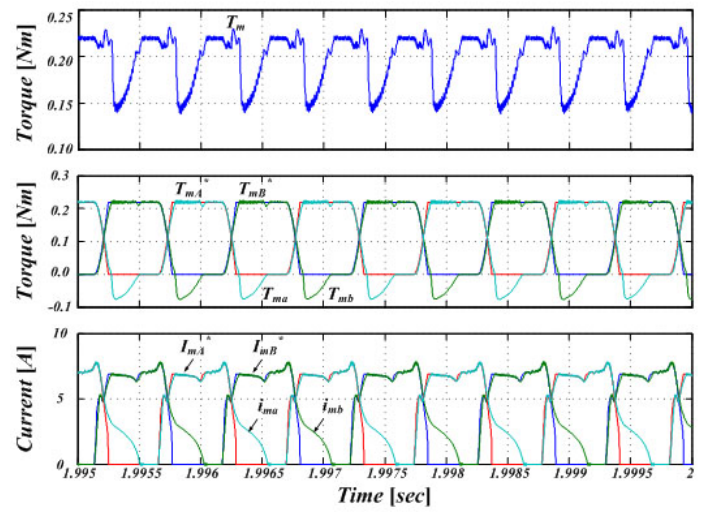

(a) Conventional cosine TSF.
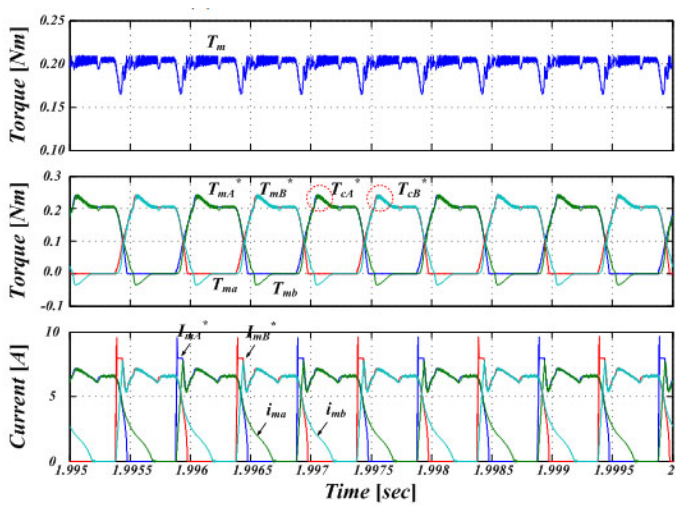

(b) Proposed TSF control scheme.

Fig. 11. Compared simulation result at 30,000[rpm].

With the conventional cosine TSF shown in Fig. 12(b), phase current can compensate the non-linear torque and constant torque can be achieved. In the proposed control scheme, the torque control performance is similar to the conventional cosine TSF. Because, the outgoing phase current can be exhausted during the commutation region, in the low speed and no load.

Fig. 13 shows the experimental results at $30,000[\mathrm{rpm}]$. As shown in Fig. 13, the current of outgoing phase is not exhausted in the commutation region. And the tail current produces torque ripple as shown in Fig. 13(a) and 13(b). In the proposed control scheme, the incoming phase current can compensate the negative torque from tail current, and the torque ripple can be much decreased as shown in Fig. 13(c).

Fig. 14 shows the experimental configurations of a practical air blower test. Fig. 15 and 16 show the experimental results with a practical heavy load fan. The fan load is increased according to the speed. In the $10,000[\mathrm{rpm}]$, output torque of the conventional cosine TSF shown in Fig. 15(a) is similar to the proposed control scheme as shown in Fig. 15(b). In this speed and load, the demagnetization current can be controlled during commutation region. However, when the speed and load are increased, the tail current which is extended to the negative torque region produces high torque ripple as shown in Fig. 16(a). As a results, the torque ripple of the conventional TSF scheme is high. The compensation current can suppress the negative torque as shown in Fig. 16(b). 


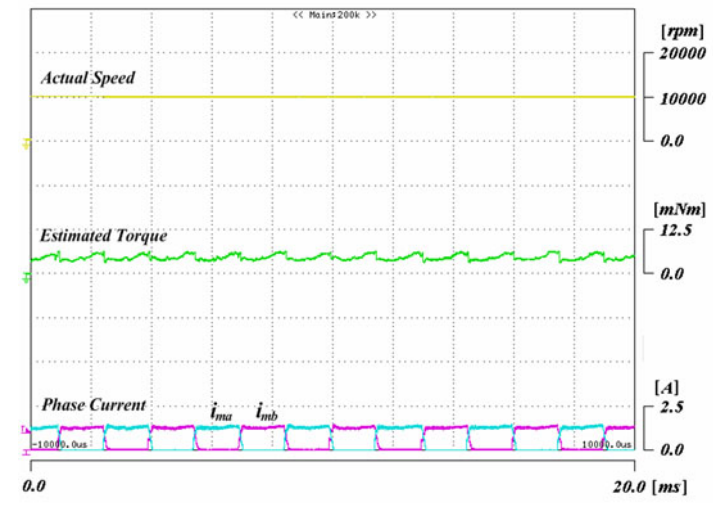

(a) PI current controller.

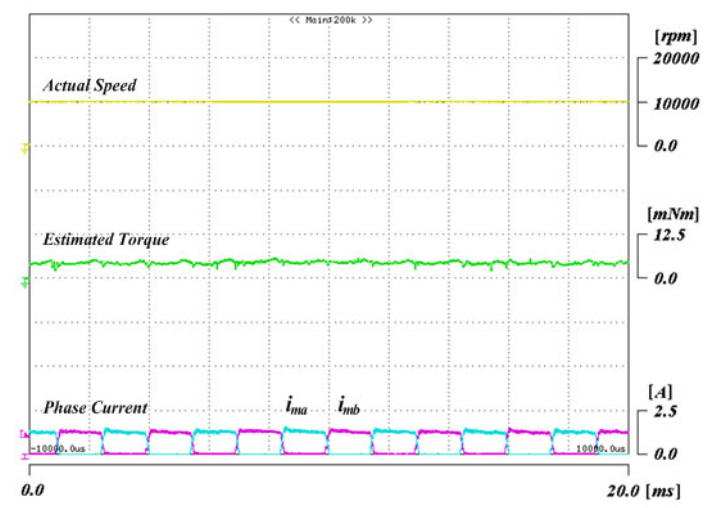

(b) Conventional cosine TSF.

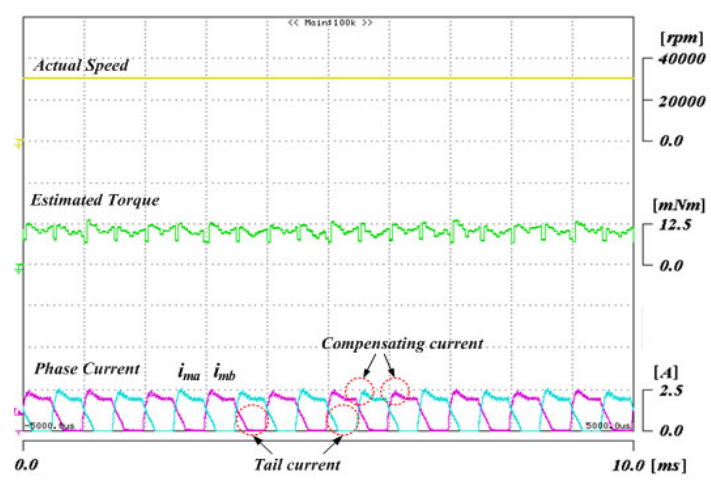

(c) Proposed TSF control scheme.

Fig. 12. Compared experimental results (At 10,000[rpm]).

\section{CONCLUSIONS}

High speed SRM has high negative torque for the tail current by a short commutation. TSF control algorithm is very effective for the torque ripple reduction due to the consideration of the non-linear inductance.

This paper presents a modified TSF control scheme for a high speed SRM. The proposed TSF control scheme has a simple torque compensator to compensate the negative torque from the tail current in a high speed region. The active phase produces an additional current to compensate negative torque of the inactive phase. From the compensation torque of the incoming phase, the negative torque of the outgoing phase can be compensated. The torque ripple due to the tail current can be reduced by the proposed control scheme in the high

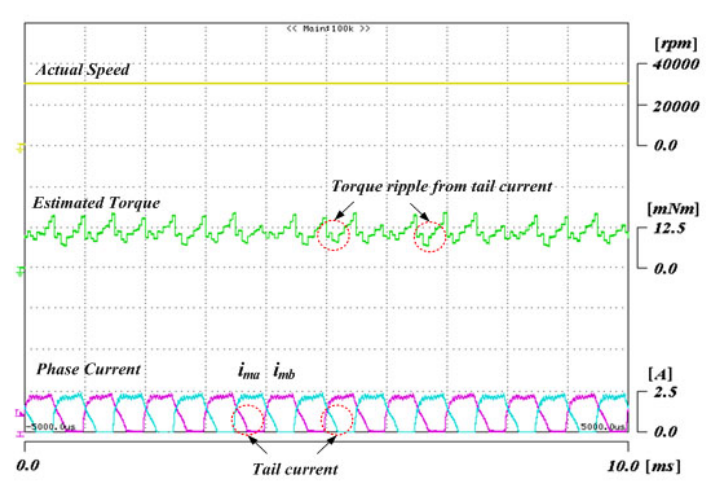

(a) PI current controller.

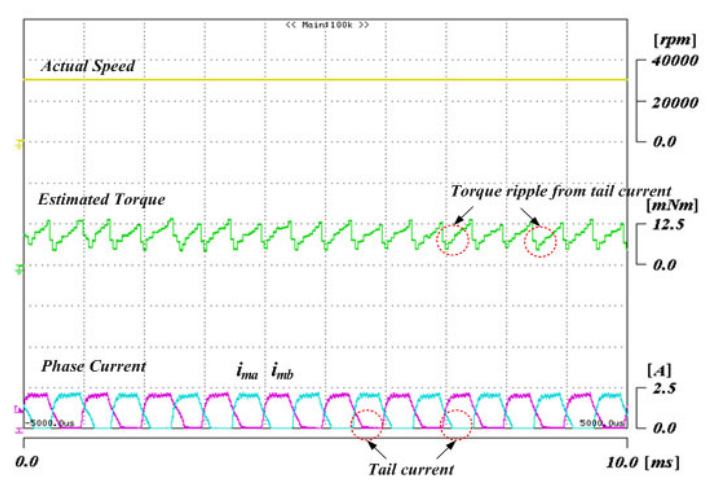

(b) Conventional cosine TSF.

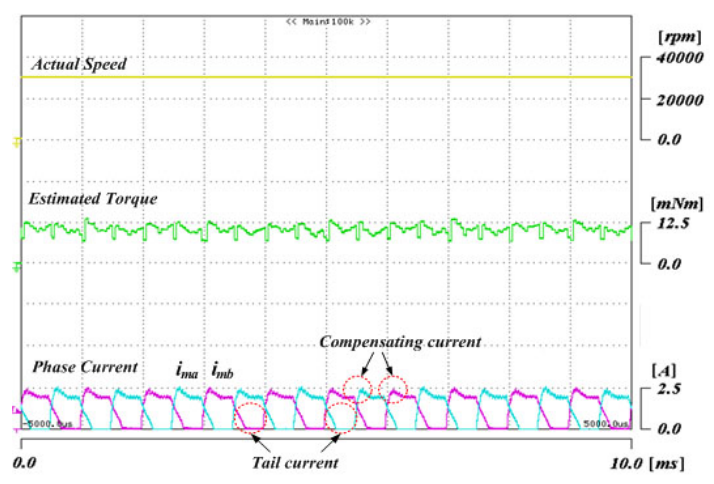

(c) Proposed TSF control scheme.

Fig. 13. Compared experimental results (At 30,000[rpm]).

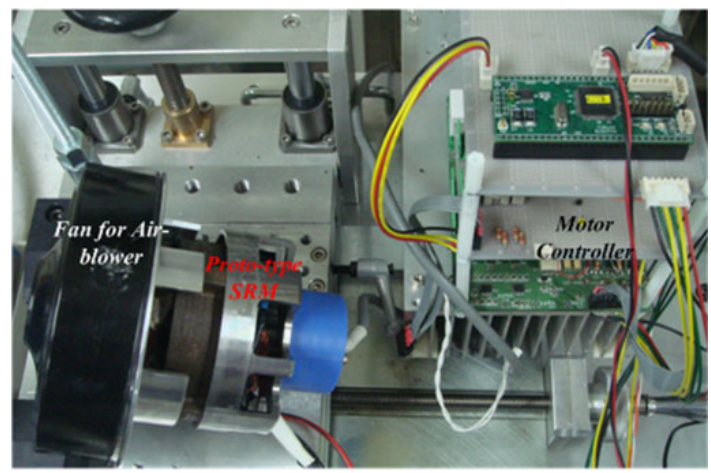

Fig. 14. Experimental configurations. 


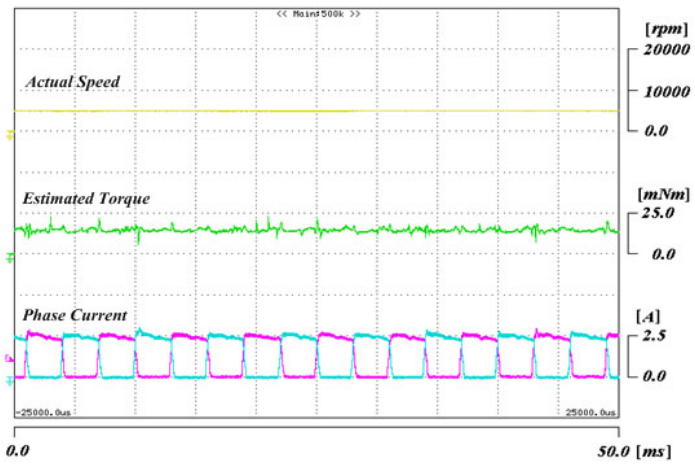

(a) Conventional cosine TSF.

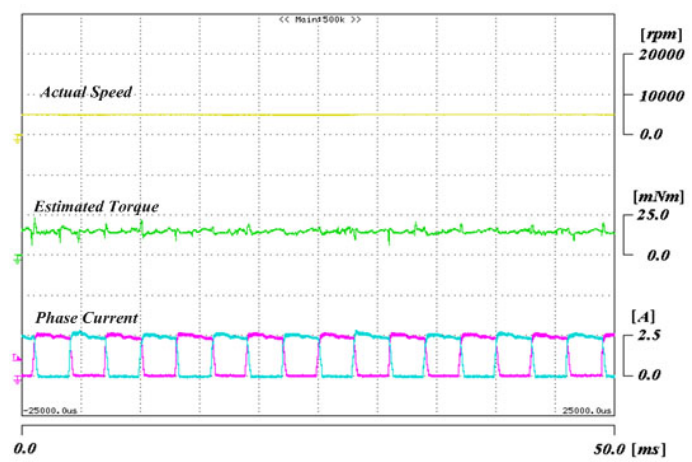

(b) Proposed TSF control scheme.

Fig. 15. Experimental results of heavy fan load (At 5,000[rpm]).

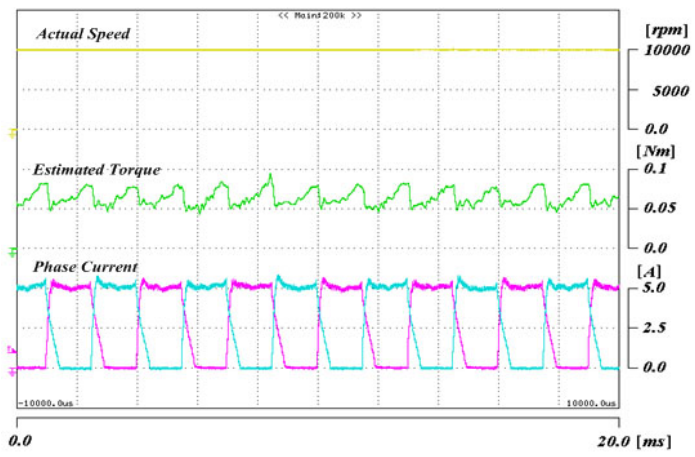

(a) Conventional cosine TSF.

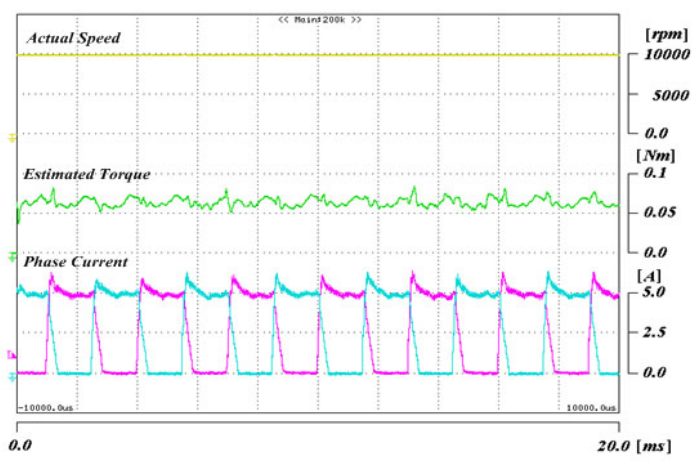

(b) Proposed TSF control scheme. speed.

The proposed control scheme is simulated and tested with the practical proto-type high speed 4/2 SRM. From the simulations and experiments, the proposed control scheme can suppress the torque ripple, and the actual speed can well keep up with the reference speed.

\section{ACKNOWLEDGMENT}

This work was supported by Energy Resource R\&D program (2009T100100654) under the Ministry of Knowledge Economy, Republic of Korea.

\section{REFERENCES}

[1] N. Bianchi, S. Bolognani, and F. Luise, "High speed drive using a slotless PM motor," IEEE Trans. Power Electron., Vol. 21, No. 4, pp. 1083-1090, Jul. 2006.

[2] S. Kozuka, N. Tanabe, J. Asama, and A. Chiba, "Basic characteristics of $150,000 \mathrm{r} / \mathrm{min}$ switched reluctance motor drive." Power and Energy Society General Meeting-Conversion and Delivery of Electrical Energy in the 21st Century, pp.1-4, Jul. 2008.

[3] D. H. Lee and J. W. Ahn, "A Novel four-level converter and instantaneous switching angle detector for high speed srm drive," IEEE Trans. Power Elctron., Vol. 22, No. 5, pp. 2034-2041, Sep. 2007.

[4] L. Xu and C. Wang, "Accurate rotor position detection and sensorless control of srm for super-high operation," IEEE Trans. Power Electron., Vol. 17, No. 5, pp. 757-763, Sep. 2002.

[5] S. H. Won, J. H. Choi, and J. Lee, "Windage loss reduction of highspeed srm using rotor magnetic saturation," IEEE Trans. Magn., Vol. 44, No. 11, pp. 4147-4150, Nov. 2008.

[6] S. M. Lukic and A. Emadi, "State-switching control technique for switched reluctance motor drives : theory and implementation," IEEE Trans. Ind. Electron., Vol. 57, No. 9, pp. 2932-2938, Sep. 2010.

[7] T. Raminosoa, B. Blunier, D. Fodorean, and A. Miraoui, "Design and optimization of a switched reluctance motor driving a compressor for a pem fuel-cell system for automotive applications," IEEE Trans. Ind. Electron., Vol. 57, No. 9, pp. 2988-2997, Sep. 2010.

[8] X. D. Xue, K. W. E. Cheng, and N. C. Cheung, "Multi-objective optimization design of in-wheel switched reluctance motors in electric vehicles," IEEE Trans. Ind. Electron., Vol. 57, No. 9, pp. 2980-2987, Sep. 2010

[9] H. Hannoun, M. Hilairet, and C. Marchand, "Design of an srm speed control strategy for a wide range of operating speeds," IEEE Trans. Ind. Electron., Vol. 57, No. 9. pp. 2911-2921, Sep. 2010.

[10] D. H. Lee and J. W. Ahn, "Design and analysis of hybrid stator bearingless srm," Journal of Electrical Engineering \& Technology, Vol. 5, No. 4, pp. 571-579, Sep. 2010.

[11] I. R. Kartono, K. Kajiwara, and H. Dohmeki, "Dynamic simulation of maximizing the starting torque for super-high-speed drive of a 4/2 Switched Reluctance Motor," IEEE International Conference of Electrical Machines and System, pp. 1-6, Sep. 2008.

[12] K. Kajiwara, Y.-J. Kim, and H. Dohmeki, "Analysis of the maximizing start torque of Switched Reluctance Motor for super high speed drive," Electrical Machines and Systems, ICEMS, pp. 1428-1432, Oct. 2007.

[13] T. Genda and H. Dohmeki, "Characteristics of $4 / 2$ switched reluctance motor for a high speed drive by the excitation angle," International Conference on Electrical Machines and Systems, ICEMS 15-18, pp.1-6, Nov. 2009.

[14] D. H. Lee, J. Liang, Z. G. Lee, J. W. Ahn, "A simple nonlinear logical torque sharing function for low torque ripple sr drive," IEEE Trans. Ind. Electron., Vol. 56, No. 8, pp. 3021-3028, Aug. 2009.

[15] S. A. Bortoff, R. R. Kohan, and R. Milman, "Adaptive control of variable relucance motors : a spline function approach," IEEE Trans. Ind, Electronics, Vol. 45, No. 3, pp. 433-444, Jun. 1998.

Fig. 16. Experimental results of heavy fan load (At 10,000[rpm]). 


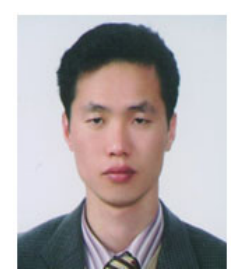

Dong-Hee Lee was born on Nov. 11, 1970 and received B.S, M.S., and $\mathrm{Ph}$. D degrees in Electrical Engineering from Pusan National University, Busan, Korea, in 1996, 1998 and 2001, respectively. He worked as a Senior Researcher of Servo R\&D Team at OTISLG, from 2002 to 2005. He has been with Kyungsung University, Busan, Korea, as an Associate professor in the Department of Mechatronics Engineering since 2005. His major research field is the Power Electronics and motor control system.

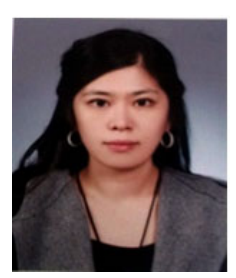

So-Yeon Ahn was born in Busan, South Korea in 1984 She received the B.S. and M.S. degrees in electrical engineering from Kyungsung University, in 2009 and 2011, respectively. Since 2011, she is working in Hanil Heavy Industry as a project engineer and attending in Ph.D course at Kyungsung University. Her current research interests are motor design and its control systems.

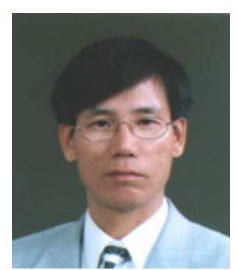

Jin-Woo Ahn was born in Busan, Korea, in 1958 He received his B.S., M.S., and Ph.D. in Electrical Engineering from Pusan National University, Busan, Korea, in 1984, 1986, and 1992, respectively. He has been with Kyungsung University, Busan, Korea, as a professor in the Department of Mechatronics Engineering since 1992. He was a visiting researcher in the Speed Lab at Glasgow University, U.K., a visiting professor in the Dept. of ECE and WEMPEC at the University of Wisconsin-Madison, USA, and a visiting professor in the Dept. of ECE at Virginia Tech. from 2006 to 2007. He was the director of the
Advance Electric Machinery and Power Electronics Center(2004 2008). He has also been the director of the Smart Mechatronics Advanced Research and Training Center since Aug. 2008 and the Senior Easy Life Regional Innovation System since July 2008, which are authorized by the Ministry of Knowledge Economy, Korea. He is the author of five books including SRM, the author of more than 120 papers and has several patents. His current research interests are advanced motor drive systems and electric vehicle drives. Dr. Ahn has received several awards including Best Paper Award(2002), Academic Achievement Award(2003), Park Min-Ho Special Award(2009) from the Korean Institute of Electrical Engineers, the Best Paper Award(2003) from the Korean Federation of Science and Technology, and Academic Achievement Award(2003), Technology Achievement Award(2004), Best Paper Award(2007) from Korean Institute of Power Electronics, respectively. He also awarded Best Research Professor (2008), Best Industrial Cooperation Award(2009) and Merit Award(2009, 2010) from Kyungsung University, respectively. He is a Fellow member of the Korean Institute of Electrical Engineers, a member of the Korean Institute of Power Electronics and a senior member of the IEEE. He is Chairman of Academic Committee, KIEE and Vice president of Korea Regional Innovation System Association. He is now serving as an Editor-in-Chief of JEESEM(Journal of Emerging Energy Systems and Electric Machines) which is a joint publication of the Korean Institute Electrical Engineers(KIEE), the Institute of Electrical Engineering of Japan(IEEJ), the China Electrotechnical Society(CES) and the Industry Application Society(IAS). 